\title{
Substantiation of Parameters of the Fibrous Material Cleaning Zone
}

\author{
Ozod Rajabov, Kurbonov Fazliddin, Shukhrat Salimov
}

\begin{abstract}
The article provides the scheme and principle of operation of the fiber material cleaning section when using multi-faceted cylinder spikes. Theoretically studied the movement of the fibrous mass on the surface of the edge of the cylinder splitting. The numerical solution of the problem substantiates the main recommended values of the parameters of the fibrous material cleaning zone. Full-factor experiments optimized the necessary system parameters. The article also investigates the influence of the annular cylinder parameters on the cleaning efficiency of the machine based on full factorial experiments. In this case, the following ring cylinder parameters are optimized: the number of revolutions is $455 \mathrm{rpm}$, the number of faces of the multifaceted spiky is 6, and the gap between the cylinder and the mesh surface is $16 \mathbf{~ m m}$.
\end{abstract}

Keywords: Cleaner, fibrous material, multifaceted spike, cylinder, moving, friction, speed, mass, optimization, cleaning effect.

\section{INTRODUCTION}

In n the existing construction, the spiked cylinder is a cleaner of fibrous material containing a cylindrical shell with strips and spikes fixed on them, set by longitudinal rows [1]. The disadvantages of spiked cylinder of the cleaner are that, due to the unsatisfactory seizure of the material by the rollers and dragging them along the perforated surface, there is a low cleaning effect. In addition, evenly installed cylinder heads lead to the monotony of the impact of the latter on the cotton bat. Since the waste is found in the raw cotton in a chaotic state at different depths, the monotony of shock impacts from the side of the cocks does not provide optimal conditions for the release of waste from arbitrary coordinates of location and occurrence on the surface of the leaves.

In the loosening cylinder of a fibrous material cleaner, to eliminate the monotony of the impact, it was proposed to create flat working surfaces on the working part of the pegs and to install in a mixed order in each row of the cylinder at

Revised Manuscript Received on February 05, 2020.

* Correspondence Author

Ozod Rajabov, Senior Lecturer (Ph.D.) Department of technological machines and equipment, Bukhara Engineering - Technological Institute. Bukhara, Uzbekistan. e-mail: ozodbek4103@mail.ru

Fazliddin Kurbonov, Candidate of Technical Sciences, Docent, Department technological machines and equipment, Bukhara Engineering Technological Institute. Bukhara, Uzbekistan.

Shukhrat Salimov, The teacher Department of technological machines and equipment, Bukhara Engineering - Technological Institute.

(C) The Authors. Published by Blue Eyes Intelligence Engineering and Sciences Publication (BEIESP). This is an open access article under the CC BY-NC-ND license (http://creativecommons.org/licenses/by-nc-nd/4.0/) an angle of 300 relative to the direction of movement of the cotton particles [2]. The disadvantage of this design is the low cleaning effect due to the significant dependence of the efficiency of the effects of the spikes on their angle of encounter with the raw cotton sheaf.

To improve the cleaning effect of fibrous material, reduce damage to cotton fibers and seeds, eliminate faces, and ensure uniform processing of the material along the entire length of the machine's working parts, the design of the loosening cylinder of the fibrous material cleaner has been improved by ensuring cyclic effects of multifaceted and cylindrical spikes alternating with fibrous material.

\section{A. Efficient cleaning cylinder designs}

The essence of the proposed design lies in the fact that the loosening cylinder contains a cylindrical surface and rows of spiky installed on it; The chess arrangement of cylindrical and multifaceted spiky allows the impact on the fibrous material with cyclically varying impulse force, which leads to the intensive release of small trash from raw cotton $[3,4,5]$.

The design consists of a cylinder 1 , cylindrical 2 and multifaceted 3 spiky installed in a staggered manner on the surface of cylinder 1 (Fig. 1).

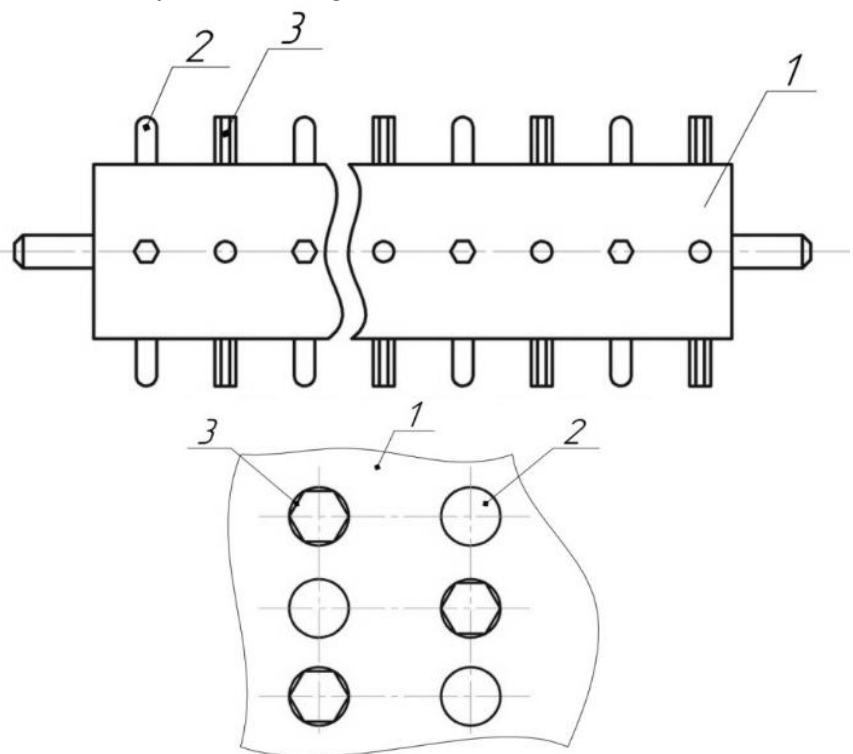

Figure 1. Loosening cylinder of fiber material cleaner

In the process of operation, during the rotation of the cylinder 1 , the spikes 2 and 3 alternately alternating with will affect the fibrous material. In this case, the impulsive force of impact on cotton will change cyclically, which leads to an intensive release of small waste from cotton. 


\section{Substantiation of Parameters of the Fibrous Material Cleaning Zone}

Depending on the characteristics of the original cotton, you can select the required number of edges spiky 3.

The use of a loosening cylinder of a fibrous material with cylindrical and multi-faceted spikes allows a significant increase in the cleaning effect.

A. Research methodology and analysis of the solution of the problem of the movement of the fibrous mass of the cylinder splitting

In the study, methods of mathematical statistics, higher mathematics, theoretical and applied mechanics, textile materials science, and primary processing of cotton were used.

In the technology of cleaning raw cotton from small waste, it is important to determine the law of movement of a particle of cotton along the flat edges of a cylinder spike. In this case, the movement of the cotton particles will be on the plane - the edges of the cylinder splitting. Therefore, during the departure of the cotton particles from the pegs, it makes a curvilinear motion, and there are components of the trajectory in the axial direction of the cylinder. The design pattern of the movement of the bat on the edge of a cylinder is shown in fig. 2. At the same time, the following forces act on a particle of raw cotton: $\bar{G}$ - weight force; $\overline{F_{c}}$ - centrifugal force; $\bar{F}_{c a r}$ - Carioles force; $\bar{F}_{f r}$ - friction force; $\bar{F}_{\text {air }}$ airflow resistance force $[6,7,8]$.

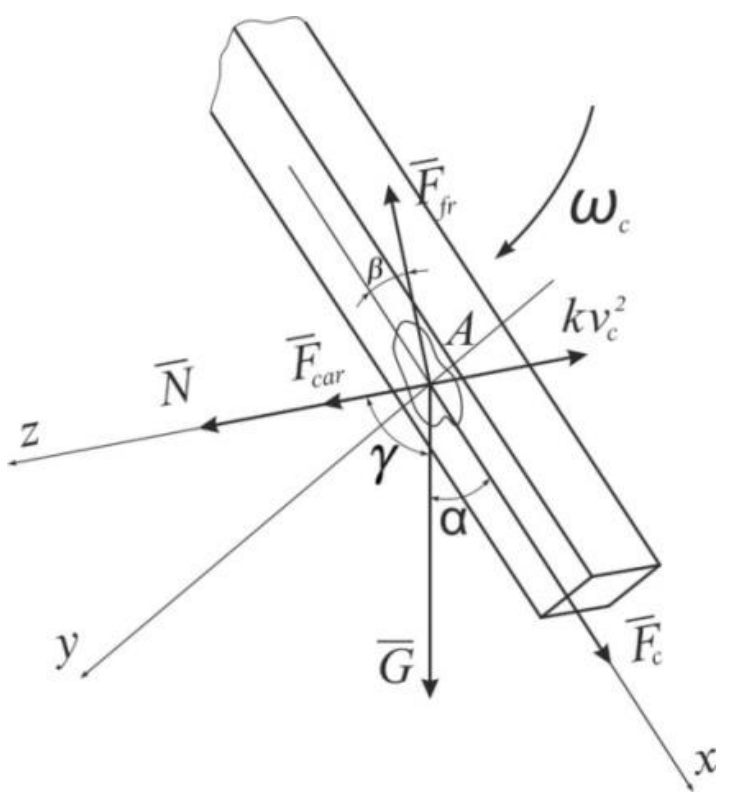

Figure 2. Calculation scheme for determining the movement of cotton hounds by a multifaceted spiky

According to the calculation scheme, using the Dalamber principle, taking into account the inertia force, the equilibrium state of the cotton sheaves on the plane of the multifaceted spiky and projecting them along the $x, y$ and $z$ axes, we have:

$$
\begin{gathered}
m_{p} \ddot{x}=m_{p} \omega_{c}^{2}\left(R_{c}+x\right)+m_{p} g \cos \alpha-f N \cos \beta \\
m_{p} \ddot{y}=m_{p} g \sin \alpha-f N \sin \beta \\
m_{p} \ddot{z}=N-2 m_{p} \omega_{c}^{2} \dot{x}-k v_{c}^{2}+m_{p} g \cos \gamma
\end{gathered}
$$

\section{RESEARCH METHODS}

where, $x, y, z$ - displacement of cotton particles along the coordinate axes; $m_{p}$ - is the mass of cotton particles; $g$ gravitational acceleration; $\omega_{C}$ - is the angular velocity of the cylinder; $R_{c}$ - the average value of the radius of the cylinder; $\mathrm{f}$ - is the coefficient of friction of the cotton particles on the surface of the edge of a cylinder; $\mathrm{N}$ - is the reaction force; $v_{c}$ is the linear cotton particles of the tangent along the tangent circle of its location on the surface of the spike; $\alpha$ - is the angle of inclination of the vector of force of weight of the bat with the $\mathrm{x}$ axis; $\beta$ - is the angle between the friction force vector with the $\mathrm{x}$ axis; $\gamma$ - is the angle between the vector of the force of weight of the bat with the coordinate axis $z$.

To solve system (3), we multiply each equation for $x, y$, and $z$. Considering that when cotton batons move along the plane of a caulk, its movement along the $z$ axis is absent. Therefore, from the third equation of system (3) we have:

$$
N=2 m_{p} \omega_{c}^{2} \dot{x}+k v_{c}^{2}+m_{p} g \cos \gamma
$$

The resulting expression (2) substituting in the first equation of the system of differential equations we get:

$$
\begin{aligned}
& m_{p} \ddot{x}=m_{p} \omega_{c}^{2} R_{c}+m_{p} \omega_{c}^{2} x+m_{p} g \cos \alpha- \\
& -2 f m_{p} \omega_{c} \dot{x} \cos \beta-k f v_{c}^{2} \cos \beta+f m_{p} g \cos \gamma \cos \beta
\end{aligned}
$$

After some transformation, we rewrite equation (3) in the following form:

$$
\begin{aligned}
& \ddot{x}-2 f \omega_{c} \dot{x} \cos \beta-\omega_{c}^{2} x=g \cos \alpha-\frac{k f v_{c}^{2} \cos \beta}{m}+ \\
& +f g \cos \gamma \cos \beta+\omega_{c}^{2} R_{c}
\end{aligned}
$$

To solve equation (4), we make the characteristic equation for its left-hand side:

$$
h^{2}-2 f \omega_{c} k-\omega_{c}^{2}=0
$$

We have a common solution in the form:

$$
x_{1}=c_{1} e^{h_{1} t}+c_{2} e^{h_{2} t}
$$

Where, $h_{1,2}=f \omega_{c} \pm \omega_{c} \sqrt{1+f^{2}}$

In this case, the expression (6) we write in the following form:

$$
x_{1}=c_{1} e^{\omega_{c} t\left(f+\sqrt{1+f^{2}}\right)}+c_{2} e^{\omega_{c} t\left(f-\sqrt{1-f^{2}}\right)}
$$

For a complete solution of the differential equation (4) we have:

$$
x=x_{1}+x_{2}
$$

Wherein

$x_{2}=A \cos \omega_{c} t+B \sin \omega_{c} t$

From (9) taking the time derivatives we have:

$$
\begin{aligned}
& \dot{x}_{2}=-\omega_{c} A \sin \omega_{c} t+\omega_{c} B \cos \omega_{c} t \\
& \dot{x}_{2}=-\omega_{c}^{2} A \cos \omega_{c} t+\omega_{c}^{2} B \sin \omega_{c} t
\end{aligned}
$$

The obtained equations (9) and (10) are substituted in (4) we get:

$$
\begin{aligned}
& -\omega_{c}^{2} A \cos \omega_{c} t-\omega_{c}^{2} B \sin \omega_{c} t+2 f \omega_{c}^{2} A \cos \beta \sin \omega_{c} t+ \\
& +2 f \omega_{c}^{2} B \cos \beta \cos \omega_{c} t-\omega_{c}^{2} A \cos \omega_{c} t-\omega_{c}^{2} B \sin \omega_{c} t= \\
& =g \cos \omega_{c} t-\frac{k f v_{c}^{2} \cos \beta}{m}+f g \cos \gamma \cos \beta+\omega_{c}^{2} R_{c}
\end{aligned}
$$



the vertical position and denoting $\alpha=\omega_{c} t$, as well as equating the coefficients in expression (11) with $\cos \omega_{c} t$ and $\sin \omega_{c} t$ we obtain a system of the following equations:

$$
\begin{aligned}
& -A+2 f B \cos \beta-A=\frac{g}{\omega_{c}^{2}} \\
& -B+2 f A \cos \beta-B=0
\end{aligned}
$$

From (12) we obtain the coefficients

$$
B=\frac{g}{2 \omega_{c}^{2} f \cos \beta} ; A=0
$$

In this case, the first particular solution according to (9) we get:

$$
x_{2}^{\prime}=\frac{g}{2 \omega_{c}^{2} f \cos \beta} \sin \omega t
$$

The particular solution $x_{2}^{\prime \prime}$ for constant values of the right-hand side of (4) will be

$$
x_{2}^{\prime \prime}=\frac{f g}{\omega_{c}^{2}} \cos \gamma \cos \beta+R_{c}-\frac{K f v_{c}^{2}}{\omega_{c}^{2} m_{p}}
$$

Then the general solution of the differential equation (4) describing the movement of the cotton batts along the face of a multifaceted cylinder splinter along the $\mathrm{x}$ axis will be:

$$
\begin{aligned}
& x_{1}=c_{1} e^{\omega_{c} t\left(f+\sqrt{1+f^{2}}\right)}+c_{2} e^{\omega_{c} t\left(f-\sqrt{1-f^{2}}\right)}+\frac{g \sin \omega t}{2 \omega_{c}^{2} f \cos \beta}+ \\
& +\frac{f g \cos \gamma \cos \beta}{\omega_{c}^{2}}+R_{c}-\frac{K f v_{c}^{2}}{m_{p} \omega_{c}^{2}}
\end{aligned}
$$

Taking into account the initial conditions of the descent of the cotton buds from the spike face at $t=0 ; x=0 ; \dot{x}=0$, and also defining $c_{1}$ and $c_{2}$, substituting them into (16) we finally get the general solution:

$$
\begin{aligned}
& x=\frac{g \sin \omega_{\tilde{\sigma}} t}{2 \omega_{c}^{2} f \cos \beta}+\frac{f g \cos \gamma \cos \beta}{\omega_{c}^{2}}+R_{c}-\frac{K f v_{c}^{2}}{m_{p} \omega_{c}^{2}}+ \\
& +\left\{R_{c} \frac{f K v_{c}^{2}}{m_{p} \omega_{c}^{2}}+\frac{g\left(1-f^{2}\right)}{2 \omega_{c}^{2}\left(1+f^{2}\right)}-\frac{1}{2 f}\left[R_{c}+\frac{g\left(1-f^{2}\right)}{2 \omega_{c}^{2}\left(1+f^{2}\right)}-\frac{f K v_{c}^{2}\left(f+\sqrt{1+f^{2}}\right)}{m_{p} \omega_{c}^{2}}\right]+\frac{g}{2 \omega_{c}^{2}\left(1+f^{2}\right)}\right\} \\
& \cdot e^{\omega_{c} t\left(f+\sqrt{1+f^{2}}\right)}+\frac{1}{2 f}\left[R_{c}+\frac{g\left(1-f^{2}\right)}{2 \omega_{c}^{2}\left(1+f^{2}\right)}-f K v_{c}^{2}\left(f+\sqrt{1+f^{2}}\right)\right] e^{\omega_{c} t\left(f-\sqrt{1+f^{2}}\right)}
\end{aligned}
$$

As noted above, the cotton fly on the verge of splitting will be mixed along the $y$ axis, that is, in the transverse direction. To determine the law of motion of the sheaves along the $y$ axis, we carry out the solution of the second differential equation of system (1). Accordingly, substituting the reaction force according to (2) into the second equation (1) we get:

$$
\begin{aligned}
& m_{p} \ddot{y}=m_{p} g \sin \alpha-2 f m_{p} \omega_{c} \dot{x} \sin \beta- \\
& -K f v_{c}^{2} \sin \beta+m_{p} f g \cos \gamma \sin \beta
\end{aligned}
$$

Given the small value and the impact on the law of the movement of cotton buckets along the $y$ axis, the Carioles force is considered insignificant. With this in mind (18) we rewrite the following form:

$$
\ddot{y}=g \sin \alpha-\frac{K f v_{c}^{2} \sin \beta}{m_{\pi}}+f g \cos \gamma \sin \beta
$$

If we consider that the right-hand side of equation (19) is denoted by $\mathrm{D}$ integrating twice in time, we get:

$$
\dot{y}=D t+c ; \quad y=D \frac{t^{2}}{2}+c_{1}^{\prime} t+c_{2}^{\prime}
$$

Given that the angle of rotation of the cylinder relative to

Where, $c_{1}^{\prime}, C_{2}^{\prime}$ - the integration constants are from the initial conditions, at $t=0 ; y=0 ; \dot{y}=0 ; c_{1}^{\prime}=0 ; c_{2}^{\prime}=0$

Then we have:

$$
\begin{aligned}
& \dot{y}=g t \sin \alpha-f \frac{K v_{c}^{2} t \sin \beta}{m_{p}}-f g t \cos \gamma \sin \beta \\
& y=\frac{g t^{2}}{2} \sin \alpha-\frac{K f v_{c}^{2} t^{2} \sin \beta}{2 m_{p}}-\frac{f g t^{2}}{2} \cos \gamma \sin \beta
\end{aligned}
$$

The numerical solution (17) and (21) is carried out with the following parameter values:

$m_{s}=(0,20 \div 0,25) g \quad ; \quad \omega_{\sigma}=(50 \div 55) s^{-1} ; f=0,35 \div 0,45 \quad ;$ $K=0,65 \div 0,70 ; R_{c p}=(0,16 \div 0,2) m ; e=2,72 ; \alpha=10^{0} \div 25^{0}$; $\beta=5^{0} \div 10^{0} ; \gamma=5^{0} \div 15^{0} ; v_{\sigma}=(5,5 \div 8,5) \mathrm{m} / \mathrm{s}$.

\section{RESULTS AND DISCUSSION}

On the basis of the numerical solution of the problem of the law of motion, the raw cotton sheaves on a flat face of the cylinder heads of the cotton cleaner from small waste were constructed graphical dependencies. In Figure 3 shows the graphical dependences of the change in the cotton batting movements along the $x$ and $y$ axes of the edge of a cylinder splitting against the change in the angular velocity of the cylinder shaft. It can be seen from them that with an increase in the angular frequency of rotation of the cylinder, the movement of the cotton buds in the flat edge of the splitting along the $\mathrm{x}$ and $\mathrm{y}$ axes increases in a nonlinear pattern.

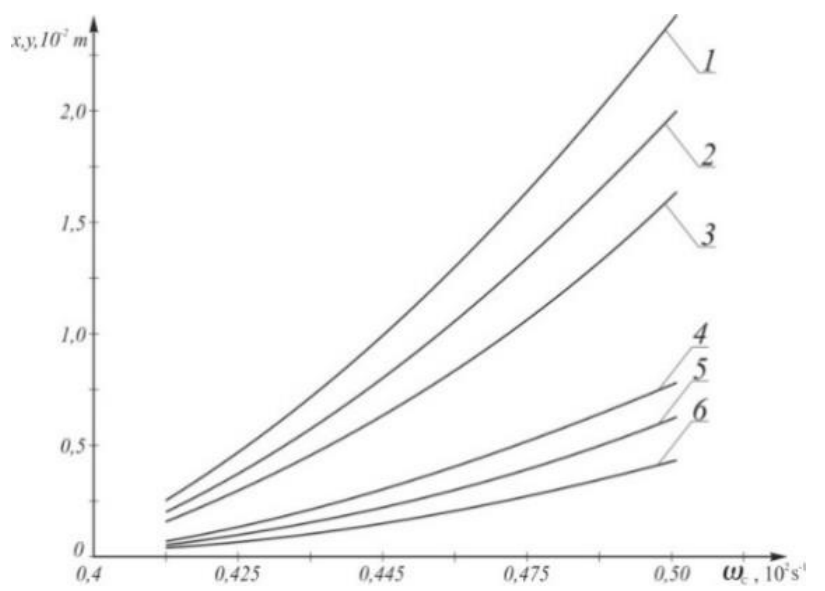

Figure 3. Depending on the change in the movements of the cotton blades along the $x$ and $y$ axes of the edge of the cylinder splitting from the change in the angular velocity of the cylinder hammer

where, 1, 2, 3 - on the $x$ axis; 4, 5, 6 - on the $y$ axis; 1,4 - at $m_{p}=0.25 \mathrm{~g}, 2,5-$ at $m_{p}=0.35 \mathrm{~g}, 3,6-$ at $m_{p}=0.45 \mathrm{~g}$,

An increase in the angular velocity of the cotton cylinder from $41.3 \mathrm{~s}^{-1}$ to $50.2 \mathrm{~s}^{-1}$ leads to an increase in the values of the cotton bat moving along the $x$ axis from $0.25 \cdot 10^{-2} \mathrm{~m}$ to $2.23 \cdot 10^{-2} \mathrm{~m}$ with a mass of $m_{p}=0.25 \mathrm{~g}$, and the bat moving along the $y$ axis increases from $0.12 \cdot 10^{-2} \mathrm{~m}$ to $0.78 \cdot 10^{-2} \mathrm{~m}$. With an increase in the mass of the cotton particle to $0.45 \mathrm{~g}$, the intensity of the displacement of cotton decreases both along the $x$ axis and along the $y$ axis.

Published By: 


\section{Substantiation of Parameters of the Fibrous Material Cleaning Zone}

So, at $m_{p}=0.45 \mathrm{~g}$, the displacement of the cotton particle along the $x$ axis on a flat edge of the cylinder splitting increases $0.17 \cdot 10^{-2} \mathrm{~m}$ to $1.54 \cdot 10^{-2} \mathrm{~m}$, while the y axis increases accordingly from $0.09 \cdot 10^{-2} \mathrm{~m}$ to $0.46 \cdot 10^{-2} \mathrm{~m}$.

This is explained by the fact that with an increase in the angular velocity, the centrifugal force increases significantly, thereby moving the cotton particle. In addition, an increase in the mass of the cotton particle leads to an increase in friction between the cotton and the flat edge of the cylinder splitting. This leads to a decrease in the intensity of movement of cotton on a flat face of a cylinder splitting. Considering that the gran spiky is at an angle to the direction of rotation of the cylinder, which leads to additional movements of the cotton particle along the $y$ axis. Moreover, the greater this angle, the greater the movement of cotton particles along the $y$ axis. In the cotton cleaning technology, this leads to an increase in the trajectory of movement of cotton buds (in the form of a zig zag), which allows additional release of trash from cotton. Therefore, the recommended values are: $\omega_{c}=(0.48 \div 0.52) \cdot 10^{2} s^{-1}, \alpha=\left(\frac{\pi}{7} \div \frac{\pi}{4}\right)$.

The trajectory of the movement of cotton raw cotton pellets along the flat face of a cylinder spiky also depends on the coefficient of friction of cotton on the surface of the hammer. The coefficient of friction of cotton on the surface of the spike mainly depends on the mass of the cotton particle. Carioles force and air resistance force as well as moisture content of the original cotton. The value of the coefficient of friction varies in the range of $0.3 \div 0.5$. In Figure 4 shows the graphical dependences of the change in the movements of raw cotton sheaves along the $\mathrm{x}$ and $\mathrm{y}$ axes along the face of a multifaceted spiky of the cylinder of the fine waste from the change in the coefficient of friction between the clap and the edge of the chopping.

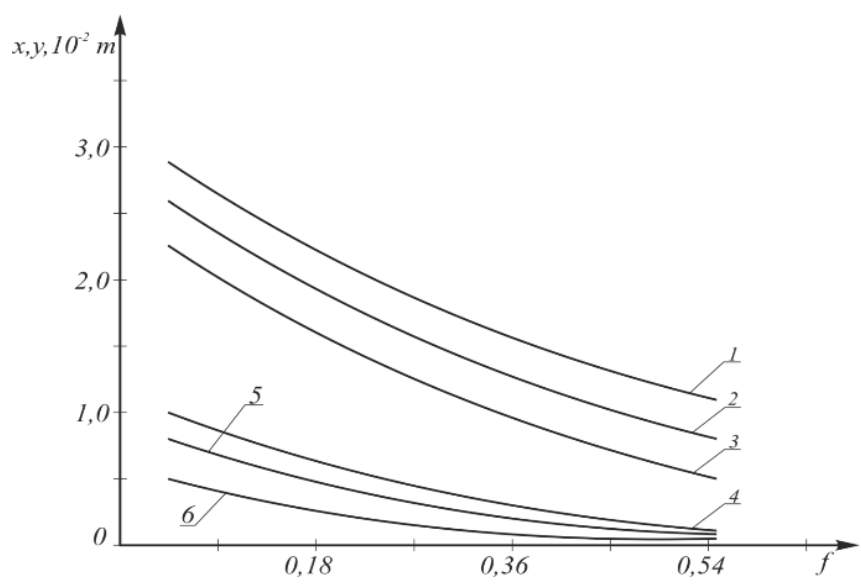

Figure 4. Graphic dependences of changes in the movements of raw cotton sheaves along the $x$ and $y$ axes along the face of a multifaceted splitting of the cylinder of a fine waste from the change in the coefficient of friction between the clap and the edge of the chopping

Where, 1, 2, 3 - on the $x$ axis; 4, 5, 6 - on the $y$ axis; 1,4 - at $\omega_{c}=48.2 \mathrm{~s}^{-1}, 2,5-$ at $\omega_{c}=50.3 \mathrm{~s}^{-1}, 3,6-$ at $\omega_{c}=53.1 \mathrm{~s}^{-1}$.

An analysis of the graphical dependences shows that with an increase in the coefficient of friction of cotton along the surface of the cylinder spiky, it leads to a decrease in the values of the movements of the cotton sheaves on the surface of the hammer, both along the $\mathrm{x}$ axis and along the $\mathrm{y}$ axis on a nonlinear dependence. So when $f$ is increased from 0.1 to 0.55 , the displacement of cotton particles along the $\mathrm{x}$ axis decreases from $2.82 \cdot 10^{-2} \mathrm{~m}$ to $1.34 \cdot 10^{-2} \mathrm{~m}$ when the angular velocity of the cylinder is $53.1 \mathrm{~s}^{-1}$, while the cotton sheaves moving along the $y$ axis decreases from $1.05 \cdot 10^{-2} \mathrm{~m}$ to $0.22 \cdot 10^{-2} \mathrm{~m}$ at an angular frequency of rotation of the cylinder with multi-faceted pegs $48.2 \mathrm{~s}^{-1}$, the movement of cotton sheaves along the $\mathrm{x}$ axis decreases from $2 \cdot 18 \cdot 10^{-2} \mathrm{~m}$ to $0.53 \cdot 10^{-2} \mathrm{~m}$. At the same time, the movement of cotton-cotton leaflet drops from $0.49 \cdot 10^{-2} \mathrm{~m}$ to $0.12 \cdot 10^{-2} \mathrm{~m}$.

It is important to study the movement of a particle of raw cotton on the flat face of the splitting of the cylinder of the cleaner of small waste at various values of the mass of cotton. In fig. Figure 5 shows the graphical dependences of the change in the displacement of the cotton particle along the $x$ and $y$ axes of the edge of a cylinder with a change in the mass of the cotton particle. An increase in the mass of the cotton particle moving along the flat surface of the spike face along the $x$ and $y$ axes leads to a decrease in the $\mathrm{x}$ and $\mathrm{y}$ values. Thus, with an increase in the mass of cotton from $0.14 \cdot 10^{-3} \mathrm{~kg}$ to $0.63 \cdot 10^{-3} \mathrm{~kg}$, the movement of cotton along the $x$ axis decreases from $2.83 \cdot 10^{-2} \mathrm{~m}$ to $1.34 \cdot 10^{-2} \mathrm{~m}$ along nonlinear regularities, while along the $y$ axis, the displacement decreases from $1.08 \cdot 10^{-2} \mathrm{~m}$ to $0.19 \cdot 10^{-2} \mathrm{~m}$ with the coefficient friction $f=0.35$. With an increase in the friction coefficient to 0.45 , the displacement of cotton sheaves along the $x$ axis decreases from $1.87 \cdot 10^{-2} \mathrm{~m}$ to $0.94 \cdot 10^{-2} \mathrm{~m}$, and to the $y$ axis from $0.71 \cdot 10^{-2} \mathrm{~m}$ to $0.21 \cdot 10^{-2} \mathrm{~m}$.

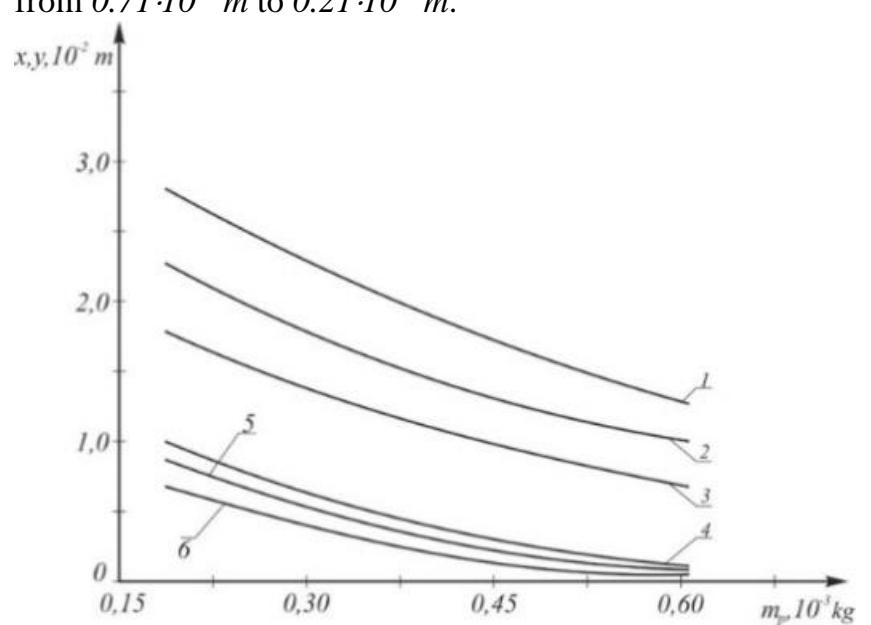

Figure 5. Graphic dependences of changes in the movements of raw cotton sheaves along the $x$ and $y$ axes along the face of a multifaceted splitting of the cylinder of a fine waste from the change in the weight of cotton shells - raw

Where, 1, 2, 3 - on the $x$ axis; 4, 5, 6 - on the $y$ axis; 1,4 - at $f=0.35 ; 2,5-$ at $f=0.4 ; 3,6-$ at $f=0.45$.

According to the analysis of the obtained research results, it can be noted that to slow down the raw cotton with a greater initial pattern, it is advisable to slow down the movement of the cotton fly, then there is a need to increase the trajectory of the cotton fly, and with less cotton weediness, the trajectory of the cotton fly must be reduced. For the options considered, the recommended parameter values are: $m_{p}=(0.2 \div 0.4) \cdot 10^{-3} \mathrm{~m}$; $f=0.3 \div 0.5 ; x=(1.2 \div 2.6) \cdot 10^{-2} \mathrm{~m}$; $y=(0.5 \div 1.0) \cdot 10^{-2} \mathrm{~m}$. 


\section{EXPERIMENT AND RESULT}

A. The results of the experiments and the optimization of the parameters of the cleaning zone of the fibrous material

In studies, the following parameters were taken as output: $x_{1}$ - frequency of rotation of the cylinder drum, $n-r p m$; $x_{2}-$ is the number of faces of a multifaceted splitting; $x_{3}$ - the gap between the spiky cylinder and the grid, $t$ $\mathrm{mm}$.

Decisions are made on a regression analysis program. At the same time, the assessment of the uniformity of the variance was carried out through the evaluation of the regression coefficients by the Student's criterion, with the adequacy of the regression models, Fisher's criteria were used $[9,10,11]$.

\begin{tabular}{|c|l|c|c|c|c|c|c|c|}
\hline \multirow{2}{*}{ № } & \multicolumn{1}{|c|}{ Name of factors } & Coding & \multicolumn{4}{c|}{ Factor values } & \multicolumn{2}{c|}{$\begin{array}{c}\text { Limits } \\
\text { of } \\
\text { change }\end{array}$} \\
\cline { 4 - 8 } & & & -1.682 & -1 & 0 & +1 & 50 \\
\hline 1. & $\begin{array}{l}\text { Frequency of rotation of the } \\
\text { cylinder, } n-r p m ;\end{array}$ & $x_{1}$ & 365.9 & 400 & 450 & 500 & 534.1 & 50 \\
\hline 2. & $\begin{array}{l}\text { is the number of faces of a } \\
\text { multifaceted spiky; }\end{array}$ & $x_{2}$ & 3 & 4 & 6 & 8 & 9.36 & 2 \\
\hline 3. & $\begin{array}{l}\text { the gap between the spiky } \\
\text { cylinder and the grid, } t- \\
\text { mm. }\end{array}$ & $x_{3}$ & 12.64 & 14 & 16 & 18 & 19.36 & 2 \\
\hline
\end{tabular}

The following regression equation was obtained [9,10]:

$$
\begin{aligned}
& Y=89.34+0.506 x_{1}+0.503 x_{2}+0.328 x_{3}+ \\
& +0.35 x_{1} x_{2}-1.3 x_{1}^{2}-0.894 x_{2}^{2}-0.894 x_{3}^{2}
\end{aligned}
$$

The output coefficients in the regression equation express the output factors and are important. The regression equation is not suitable for practical calculations, so the transition from the coded values $\left(x_{1}, x_{2}, x_{3}\right)$ to the actual values of the factors $(n, \kappa, \delta)$ is carried out by the following expressions

$$
x_{1}=\frac{n-n_{0}}{\Delta n} ; x_{2}=\frac{\kappa-\kappa_{0}}{\Delta \kappa} ; x_{3}=\frac{\delta-\delta_{0}}{\Delta \delta} ;
$$

Where, $n_{0}, \kappa_{0}, \delta_{0}$ are real values of the basic equations, $\Delta n$, $\Delta \kappa, \Delta \delta$ are intermediate values. Substituting the values $n_{0}, \kappa_{0}$, $\delta_{0}$ and $\Delta n, \Delta \kappa, \Delta \delta$ into formula (12), we get:

$$
x_{1}=\frac{n-450}{50} ; x_{2}=\frac{\kappa-6}{2} ; x_{3}=\frac{\delta-1}{0,5} ;
$$

From expression (24) I get the factor equations in the following form:

$$
\begin{aligned}
& K_{c}=-44.85+0.457 n+1.36 \kappa+7.8 \delta+ \\
& +3.5 \cdot 10^{-3} n \kappa-5.2 \cdot 10^{-4} n^{2}-0.22 \kappa^{2}-3.57 \delta^{2}
\end{aligned}
$$

In order to clarify the study, the numerical solution of the equation was carried out using a computer using the EXCEL program and graphs were obtained (Fig. 6,7,8)

Fig. 6 shows the graphical dependences of the change in the cleaning effect on the rotational speed of the cylinder. The first graph in the diagram is given, respectively, for low values of $x_{2}$ and $x_{3}$, the second graph for intermediate values, and the third for higher values.

The graphs show that when the rotational speed of the cylinder is hanging from $400 \mathrm{rpm}$ to $500 \mathrm{rpm}$, the non-linear character influences the cleaning effect of the input parameters.

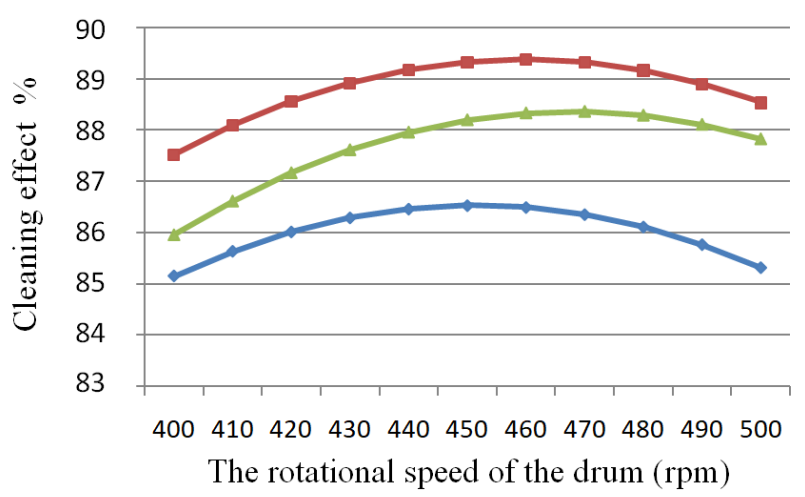

Figure 6. The dependence of the cleaning effect on the rotational speed of the cylinder

The first graph in the diagram shows the cleaning effect at low values of $x_{2}=4, x_{3}=14 \mathrm{~mm}$, while the cylinder rotation speed of $400 \mathrm{rpm}$ with increasing rotational speed to $450 \mathrm{rpm}$, the cleaning effect increased to $86.5 \%$, and at $500 \mathrm{rpm}$ the cleaning effect was reduced to $85.3 \%$. The second graph was obtained with average values of $x_{2}=6, x_{3}=16 \mathrm{~mm}$. With an increase in the speed of the cylinder from 400 to $460 \mathrm{rpm}$, the cleaning effect increases to a maximum of $89.4 \%$. However, with an increase in rotational speeds up to $500 \mathrm{rpm}$, the cleaning effect decreased to $88.5 \%$. The third graph was obtained at $x_{2}=6, x_{3}=18 \mathrm{~mm}$ and at $n=400 \mathrm{rpm}$ with a cleaning effect of $86 \%$. With an increase in $n=470 \mathrm{rpm}$, the cleaning effect increased to $88.4 \%$, with a further increase in $n=500 \mathrm{rpm}$, the cleaning effect decreased to $87.8 \%$. Experiments have shown that at low frequencies of rotation of the spindle cylinder the cleaning effect is low. With an increase in the frequency of rotation of the ring cylinder to $n$ $=500 \mathrm{rpm}$, the raw cotton quickly leaves the cleaning zone and does not have time to release trash impurities and the cleaning effect decreases. A high cleaning effect is observed at $n=450$ - $460 \mathrm{rpm}$, i.e. makes up $89.4 \%$

Figure 7 shows the graphs of the dependence of the cleaning effect, depending on the multifaceted spiky 


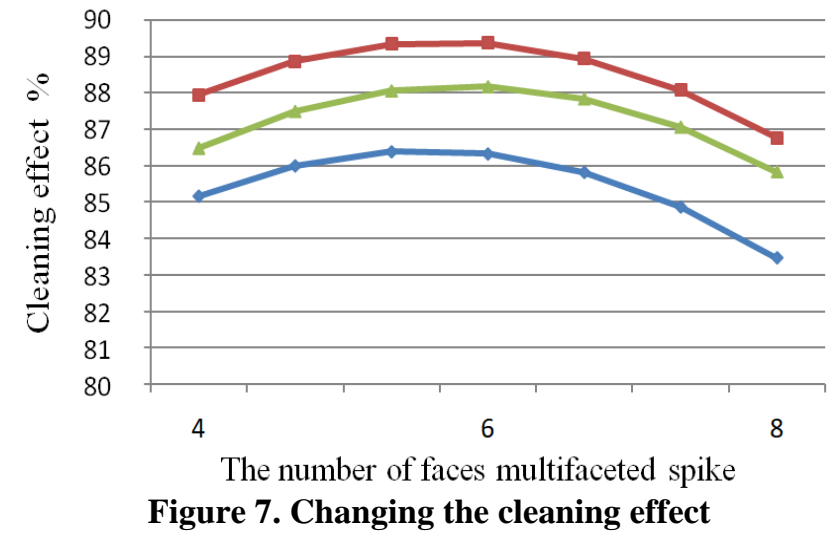

In fig. 8 shows the graphical dependences of the change in the cleaning effect on shallow waste at high values of the input parameters.

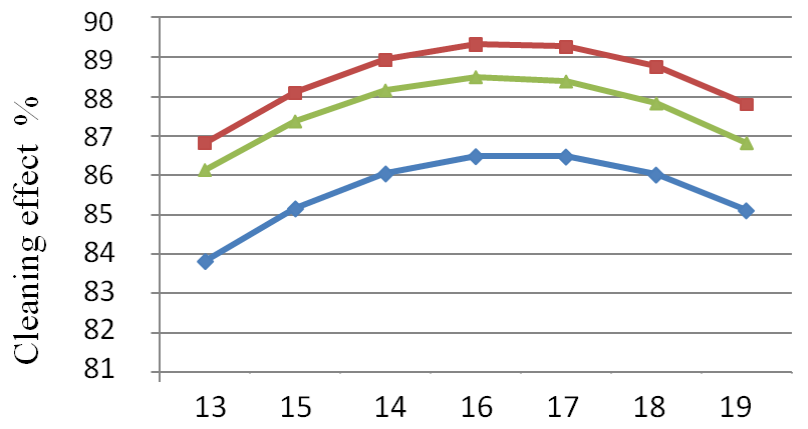

The gap between the spiky cylinder and the grid Figure 8. Changing the cleaning effect

On the basis of the full-factor experiments, the best parameters were determined to clean the cotton from small waste: the number of edges of the pegs 6 , the technological gap between the pegs and the net was $16 \mathrm{~mm}$, the number of cylinder revolutions was $455 \mathrm{rpm}$, at which the maximal effect cleaned the cotton from fine waste to $89.4 \%$

\section{CONCLUSION}

An effective design scheme of the cylinder with a combined arrangement of multifaceted and circular spiky on its surface has been developed. On the basis of the full-factor experiments, the best parameters were determined to clean the cotton from fine waste: the number of edges of the spiky 6 , the technological gap between the spiky and the net is 16 $\mathrm{mm}$, the cylinder speed is $455 \mathrm{rpm}$, at which the maximal effect of clearing cotton from fine waste to $89.4 \%$.

\section{REFERENCES}

1. Djurayev A., Rajabov O. "Substantiation of the main parameters of the cylinder with multifaceted spiked of the cotton cleaner from small waste". International scientific and practical conference "Innovative ideas of modern youth in science and education", 2019. USA. pp. 149-151 http://conf.researchparks.org/

2. Mavlyanov Aybek, Rajabov Ozod, Yakubova Aziza. "Study of The Influence of the Parameters of the Plastic Grate on Elastic Supports With Nonlinear Stiffness on the Oscillation Frequency". International scientific and practical conference "Innovative ideas of modern youth in science and education”, 2019. USA. pp. 152-154 http://conf.researchparks.org/

3. Sanh Le. Cleaning Performance of Modified Cylinder Cleaners. / The Journal of Cotton Science 10:273-283 (2006). http://journal.cotton.org.

4. Juraev Anvar, Rajabov Ozod. "Analysis of the Interaction of Fibrous Material with a Multifaceted Grid of the Cleaner". International Journal

of Recent Technology and Engineering (IJRTE) ISSN: 2277-3878, Volume-8, Issue-1, May 2019/ pp. 2661-2666

5. Djuraev A., Rajabov O.I. "Experimental study of the interaction of multifaceted and cylindrical spiky cylinder in cotton cleaner from small waste". International Journal of Advanced Research in Science Engineering and Technology Vol. 6, Issue 3, 2019. pp. 8376-8381. http://www.ijarset.com/volume-6-issue-3.html

6. Ozod Rajabov, Ziyodullo Shodiyev. "Analysis of Small Fluctuations of a Multifaceted Mesh under the Influence of Technological Load from the Cleaned Cotton - Raw". International Journal of Advanced Research in Science, Engineering and Technology. Vol. 6, Issue 10, October 2019.

http://www.ijarset.com/upload/2019/october/74-ozodbek-72.pdf

7. Rajabov O.I. "The influence of the mode of movement of the pieces cotton when interacting with a cotton grid". International Journal of Advanced Research in Science, Engineering and Technology. Vol. 6, Issue 3, 2019. pp. 8455-8381.

http://www.ijarset.com/volume-6-issue-3.htm

8. Mavlyanov A.P., Djuraev A. Pin drum with the polyhedral splits of raw cotton cleaner. European Sciences review Scientific journal № 7-8 2017 p.104-106.

http://ppublishing.org/upload/iblock/23f/ESR_7-8_2017.pdf

9. Dzhuraev A.D., Daliyev Sh. L. "Development of the design and justification of the parameters of the composite flail drum of a cotton cleaner”. European Sciences review Scientific journal № 7-8 2017 p. 96-100. http://ppublishing.org/upload/iblock/23f/ESR_7-8_2017.pdf

10. Musalimov V.M., Sergushin P.A. "Analytical mechanics. Lagrange equation of the second kind. Free vibrations". Study Guide. - St. Petersburg: ITMO St. Petersburg State University, 2007. - 53 p.

11. Rosulov R K., Saphoyev A.A. To the problems of cleaning of hard grades raw cotton. Journal of Textile Science \& Engineering. Volume 5 Issue 2. April 2015/ P. 67-72

\section{AUTHORS PROFILE}
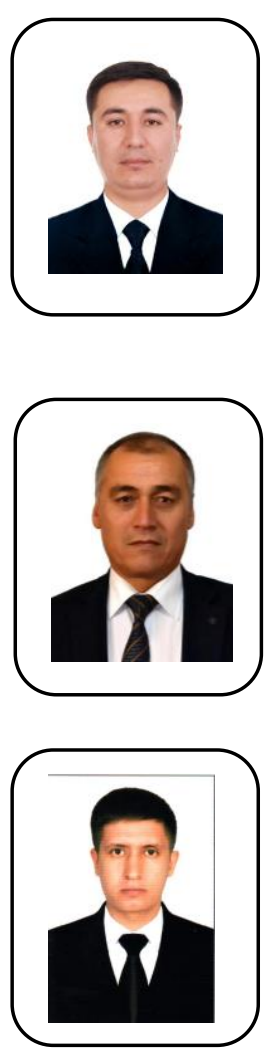

Ozod Rajabov, Doctor of Philosophy in Technical Sciences (PhD) The author of more than 40 scientific and methodological works, including 12 scientific articles, of which 5 Scopus journals have 3 international databases, 3 patents for inventions. Senior Lecturer (Ph.D.) Department of technological machines and equipment, Bukhara Engineering - Technological Institute. Bukhara, Uzbekistan. e-mail: ozodbek4103@mail.ru, phone: +99891-3087504

Fazliddin Kurbonov, Candidate of Technical Sciences, Docent, Department technological machines and equipment, Bukhara Engineering Technological Institute. Bukhara, Uzbekistan

Shukhrat Salimov, The teacher Department of technological machines and equipment, Bukhara Engineering - Technological Institute. 